\title{
Futures hedge ratios: a review
}

\author{
Sheng-Syan Chen ${ }^{\mathrm{a}, *}$, Cheng-few Lee ${ }^{\mathrm{b}, \mathrm{c}}$, Keshab Shrestha ${ }^{\mathrm{d}, \mathrm{e}}$ \\ a Department of Finance, College of Management, Yuan Ze University, \\ 135 Yuan-Tung Road, Chung-Li, Taoyuan, Taiwan, ROC \\ ${ }^{\mathrm{b}}$ Department of Finance, Rutgers University, New Brunswick, NJ, USA \\ ${ }^{\mathrm{c}}$ Graduate Institute of Finance, National Chiao Tung University, Taiwan, ROC \\ ${ }^{d}$ Nanyang Business School, Nanyang Technological University, Singapore \\ ${ }^{\mathrm{e}}$ Faculty of Administration, University of Regina, Regina, Sask., Canada
}

Received 18 May 2001; received in revised form 22 February 2002; accepted 7 June 2002

\begin{abstract}
This paper presents a review of different theoretical approaches to the optimal futures hedge ratios. These approaches are based on minimum variance, mean-variance, expected utility, mean extended-Gini coefficient, as well as semivariance. Various ways of estimating these hedge ratios are also discussed, ranging from simple ordinary least squares to complicated heteroscedastic cointegration methods. Under martingale and joint-normality conditions, different hedge ratios are the same as the minimum variance hedge ratio. Otherwise, the optimal hedge ratios based on the different approaches are different and there is no single optimal hedge ratio that is distinctly superior to the remaining ones.

(C) 2002 Board of Trustees of the University of Illinois. All rights reserved.
\end{abstract}

JEL classification: $\mathrm{C} 130$

Keywords: Hedge ratio; Semivariance; Cointegration; Minimum variance; Gini coefficient

\section{Introduction}

One of the best uses of derivative securities such as futures contracts is in hedging. In the past, both academicians and practitioners have shown great interest in the issue of hedging with futures. This is quite evident from the large number of articles written in this area.

${ }^{*}$ Corresponding author. Tel.: +886-3-4638800x667; fax: +886-3-4354624.

E-mail address: fnschen@saturn.yzu.edu.tw (S.-S. Chen). 
One of the main theoretical issues in hedging involves the determination of the optimal hedge ratio. However, the optimal hedge ratio depends on the particular objective function to be optimized. Many different objective functions are currently being used. For example, one of the most widely-used hedging strategies is based on the minimization of the variance of the hedged portfolio (e.g., see Ederington, 1979; Johnson, 1960; Myers \& Thompson, 1989). This so-called minimum variance (MV) hedge ratio is simple to understand and estimate. However, the MV hedge ratio completely ignores the expected return of the hedged portfolio. Therefore, this strategy is in general inconsistent with the mean-variance framework unless the individuals are infinitely risk averse or the futures price follows a pure martingale process (i.e., expected futures price change is zero).

Other strategies that incorporate both the expected return and risk (variance) of the hedged portfolio have been recently proposed (e.g., see Cecchetti, Cumby, \& Figlewski, 1988; Howard \& D’Antonio, 1984; Hsin, Kuo, \& Lee, 1994). These strategies are consistent with the meanvariance framework. However, it can be shown that if the futures price follows a pure martingale process, then the optimal mean-variance hedge ratio will be the same as the MV hedge ratio.

Another aspect of the mean-variance-based strategies is that even though they are an improvement over the MV strategy, for them to be consistent with the expected utility maximization principle, either the utility function needs to be quadratic or the returns should be jointly normal. If neither of these assumptions is valid, then the hedge ratio may not be optimal with respect to the expected utility maximization principle. Some researchers have solved this problem by deriving the optimal hedge ratio based on the maximization of the expected utility (e.g., see Cecchetti et al., 1988; Lence, 1995, 1996). However, this approach requires the use of specific utility function and specific return distribution.

Attempts have been made to eliminate these specific assumptions regarding the utility function and return distributions. Some of them involve the minimization of the mean extended-Gini (MEG) coefficient, which is consistent with the concept of stochastic dominance (e.g., see Cheung, Kwan, \& Yip, 1990; Kolb \& Okunev, 1992, 1993; Lien \& Luo, 1993a; Lien \& Shaffer, 1999; Shalit, 1995). Shalit (1995) shows that if the prices are normally distributed, then the MEG-based hedge ratio will be the same as the MV hedge ratio.

Recently, hedge ratios based on the generalized semivariance (GSV) or lower partial moments have been proposed (e.g., see Chen, Lee, \& Shrestha, 2001; De Jong, De Roon, \& Veld, 1997; Lien \& Tse, 1998, 2000). These hedge ratios are also consistent with the concept of stochastic dominance. Furthermore, these GSV-based hedge ratios have another attractive feature whereby they measure portfolio risk by the GSV, which is consistent with the risk perceived by managers, because of its emphasis on the returns below the target return (see Crum, Laughhunn, \& Payne, 1981; Lien \& Tse, 2000). Lien and Tse (1998) show that if the futures and spot returns are jointly normally distributed and if the futures price follows a pure martingale process, then the minimum-GSV hedge ratio will be equal to the MV hedge ratio.

Most of the studies mentioned above (except Lence, 1995, 1996) ignore transaction costs as well as investments in other securities. Lence $(1995,1996)$ derives the optimal hedge ratio where transaction costs and investments in other securities are incorporated in the model. Using a CARA utility function, Lence finds that under certain circumstances, the optimal hedge ratio is zero; i.e., the optimal hedging strategy is not to hedge at all. 
In addition to the use of different objective functions in the derivation of the optimal hedge ratio, previous studies also differ in terms of the dynamic nature of the hedge ratio. For example, some studies assume that the hedge ratio is constant over time. Consequently, these static hedge ratios are estimated using unconditional probability distributions (e.g., see Benet, 1992; Ederington, 1979; Ghosh, 1993; Howard \& D’Antonio, 1984; Kolb \& Okunev, 1992, 1993). On the other hand, several studies allow the hedge ratio to change over time. In some cases, these dynamic hedge ratios are estimated using conditional distributions associated with models such as ARCH and GARCH (e.g., see Baillie \& Myers, 1991; Cecchetti et al., 1988; Kroner \& Sultan, 1993; Sephton, 1993a). Alternatively, the hedge ratios can be made dynamic by considering a multi-period model where the hedge ratios are allowed to vary for different periods. This is the method used by Lien and Luo (1993b).

When it comes to estimating the hedge ratios, many different techniques are currently being employed, ranging from simple to complex ones. For example, some of them use such a simple method as the ordinary least squares (OLS) technique (e.g., see Benet, 1992; Ederington, 1979; Malliaris \& Urrutia, 1991). However, others use more complex methods such as the conditional heteroscedastic (ARCH or GARCH) method (e.g., see Baillie \& Myers, 1991; Cecchetti et al., 1988; Sephton, 1993a), the random coefficient method (e.g., see Grammatikos \& Saunders, 1983), the cointegration method (e.g., see Chou, Fan, \& Lee, 1996; Ghosh, 1993; Lien \& Luo, 1993b), or the cointegration-heteroscedastic method (e.g., see Kroner \& Sultan, 1993).

It is quite clear that there are several different ways of deriving and estimating hedge ratios. In the paper we review these different techniques and approaches and examine their relations.

The paper is divided into five sections. In Section 2 alternative theories for deriving the optimal hedge ratios are reviewed. Various estimation methods are discussed in Section 3. Section 4 presents a discussion on the relationship among lengths of hedging horizon, maturity of futures contract, data frequency, and hedging effectiveness. Finally, in Section 5 we provide a summary and conclusion.

\section{Alternative theories for deriving the optimal hedge ratio}

The basic concept of hedging is to combine investments in the spot market and futures market to form a portfolio that will eliminate (or reduce) fluctuations in its value. Specifically, consider a portfolio consisting of $C_{s}$ units of a long spot position and $C_{f}$ units of a short futures position. ${ }^{1}$ Let $S_{t}$ and $F_{t}$ denote the spot and futures prices at time $t$, respectively. Since the futures contracts are used to reduce the fluctuations in spot positions, the resulting portfolio is known as the hedged portfolio. The return on the hedged portfolio, $R_{h}$, is given by:

$$
R_{h}=\frac{C_{s} S_{t} R_{s}-C_{f} F_{t} R_{f}}{C_{s} S_{t}}=R_{s}-h R_{f},
$$

where $h=C_{f} F_{t} / C_{s} S_{t}$ is the so-called hedge ratio, and $R_{s}=\left(S_{t+1}-S_{t}\right) / S_{t}$ and $R_{f}=$ $\left(F_{t+1}-F_{t}\right) / F_{t}$ are so-called one-period returns on the spot and futures positions, respectively. Sometimes, the hedge ratio is discussed in terms of price changes (profits) instead of returns. 
In this case the profit on the hedged portfolio, $\Delta V_{H}$, and the hedge ratio, $H$, are respectively given by:

$$
\Delta V_{H}=C_{s} \Delta S_{t}-C_{f} \Delta F_{t} \quad \text { and } \quad H=\frac{C_{f}}{C_{s}},
$$

where $\Delta S_{t}=S_{t+1}-S_{t}$ and $\Delta F_{t}=F_{t+1}-F_{t}$.

The main objective of hedging is to choose the optimal hedge ratio (either $h$ or $H$ ). As mentioned above, the optimal hedge ratio will depend on a particular objective function to be optimized. Furthermore, the hedge ratio can be static or dynamic. In Sections 2.1 and 2.2, we will discuss the static hedge ratio and then the dynamic hedge ratio.

It is important to note that in the above setup, the cash position is assumed to be fixed and we only look for the optimum futures position. Most of the hedging literature assumes that the cash position is fixed, a setup that is suitable for financial futures. However, when we are dealing with commodity futures, the initial cash position becomes an important decision variable that is tied to the production decision. One such setup considered by Lence $(1995,1996)$ will be discussed in Section 2.3.

\subsection{Static case}

We consider here that the hedge ratio is static if it remains the same over time. The static hedge ratios reviewed in this paper can be divided into eight categories, as shown in Table 1 . We will discuss each of them in the paper.

\subsubsection{Minimum variance hedge ratio}

The most widely-used static hedge ratio is the MV hedge ratio. Johnson (1960) derives this hedge ratio by minimizing the portfolio risk, where the risk is given by the variance of changes

Table 1

A list of different static hedge ratios

\begin{tabular}{ll}
\hline Hedge ratio & Objective function \\
\hline MV hedge ratio & Minimize variance of $R_{h}$ \\
Optimum mean-variance hedge ratio & Maximize $E\left(R_{h}\right)-\frac{1}{2} A \operatorname{Var}\left(R_{h}\right)$ \\
Sharpe hedge ratio & Maximize $\frac{E\left(R_{h}\right)-R_{F}}{\sqrt{\operatorname{Var}\left(R_{h}\right)}}$ \\
Maximum expected utility hedge ratio & Maximize $E\left[U\left(W_{1}\right)\right]$ \\
Minimum MEG coefficient hedge ratio & Minimize $\Gamma_{v}\left(R_{h} v\right)$ \\
Optimum mean-MEG hedge ratio & Maximize $E\left[R_{h}\right]-\Gamma_{v}\left(R_{h} v\right)$ \\
Minimum GSV hedge ratio & Minimize $V_{\delta, \alpha}\left(R_{h}\right)$ \\
Maximum mean-GSV hedge ratio & Maximize $E\left[R_{h}\right]-V_{\delta, \alpha}\left(R_{h}\right)$ \\
\hline
\end{tabular}

Notes: (1) $R_{h}$ : return on the hedged portfolio; $E\left(R_{h}\right)$ : expected return on the hedged portfolio; $\operatorname{Var}\left(R_{h}\right)$ : variance of return on the hedged portfolio; $A$ : risk aversion parameter; $R_{F}$ : return on the risk-free security; $E\left(U\left(W_{1}\right)\right)$ : expected utility of end-of-period wealth; $\Gamma_{v}\left(R_{h} v\right)$ : mean extended-Gini coefficient of $R_{h} ; V_{\delta, \alpha}\left(R_{h}\right)$ : generalized semivariance of $R_{h}$. (2) With $W_{1}$ given by Eq. (15), the maximum expected utility hedge ratio includes the hedge ratio considered by Lence $(1995,1996)$. 
in the value of the hedged portfolio as follows:

$$
\operatorname{Var}\left(\Delta V_{H}\right)=C_{s}^{2} \operatorname{Var}(\Delta S)+C_{f}^{2} \operatorname{Var}(\Delta F)-2 C_{s} C_{f} \operatorname{Cov}(\Delta S, \Delta F)
$$

The MV hedge ratio, in this case, is given by:

$$
H_{J}^{*}=\frac{C_{f}}{C_{s}}=\frac{\operatorname{Cov}(\Delta S, \Delta F)}{\operatorname{Var}(\Delta F)} .
$$

Alternatively, if we use definition (1a) and use $\operatorname{Var}\left(R_{h}\right)$ to represent the portfolio risk, then the MV hedge ratio is obtained by minimizing $\operatorname{Var}\left(R_{h}\right)$ which is given by:

$$
\operatorname{Var}\left(R_{h}\right)=\operatorname{Var}\left(R_{s}\right)+h^{2} \operatorname{Var}\left(R_{f}\right)-2 h \operatorname{Cov}\left(R_{s}, R_{f}\right)
$$

In this case, the MV hedge ratio is given by:

$$
h_{J}^{*}=\frac{\operatorname{Cov}\left(R_{s}, R_{f}\right)}{\operatorname{Var}\left(R_{f}\right)}=\rho \frac{\sigma_{s}}{\sigma_{f}},
$$

where $\rho$ is the correlation coefficient between $R_{s}$ and $R_{f}$, and $\sigma_{s}$ and $\sigma_{f}$ are standard deviations of $R_{s}$ and $R_{f}$, respectively.

The attractive features of the MV hedge ratio are that it is easy to understand and simple to compute. However, in general the MV hedge ratio is not consistent with the mean-variance framework since it ignores the expected return on the hedged portfolio. For the MV hedge ratio to be consistent with the mean-variance framework, either the investors need to be infinitely risk averse or the expected return on the futures contract needs to be zero.

\subsubsection{Optimum mean-variance hedge ratio}

Various studies have incorporated both risk and return in the derivation of the hedge ratio. For example, Hsin et al. (1994) derive the optimal hedge ratio that maximizes the following utility function:

$$
\max _{C_{f}} V\left(E\left(R_{h}\right), \sigma ; A\right)=E\left(R_{h}\right)-0.5 A \sigma_{h}^{2},
$$

where $A$ represents the risk aversion parameter. It is clear that this utility function incorporates both risk and return. Therefore, the hedge ratio based on this utility function would be consistent with the mean-variance framework. The optimal number of futures contract and the optimal hedge ratio are respectively given by:

$$
h_{2}=-\frac{C_{f}^{*} F}{C_{s} S}=-\left[\frac{E\left(R_{f}\right)}{A \sigma_{f}^{2}}-\rho \frac{\sigma_{s}}{\sigma_{f}}\right] .
$$

One problem associated with this type of hedge ratio is that in order to derive the optimum hedge ratio, we need to know the individual's risk aversion parameter. Furthermore, different individuals will choose different optimal hedge ratios, depending on the values of their risk aversion parameter.

Since the MV hedge ratio is easy to understand and simple to compute, it will be interesting and useful to know under what condition the above hedge ratio would be the same as the 
MV hedge ratio. It can be seen from Eqs. (2b) and (4) that if $A \rightarrow \infty$ or $E\left(R_{f}\right)=0$, then $h_{2}$ would be equal to the MV hedge ratio $h_{J}^{*}$. The first condition is simply a restatement of the infinitely risk-averse individuals. However, the second condition does not impose any condition on the risk averseness, and this is important. It implies that even if the individuals are not infinitely risk averse, the MV hedge ratio would be the same as the optimal mean-variance hedge ratio if the expected return on the futures contract is zero (i.e., futures prices follow a simple martingale process). Therefore, if futures prices follow a simple martingale process, then we do not need to know the risk aversion parameter of the investor to find the optimal hedge ratio.

\subsubsection{Sharpe hedge ratio}

Another way of incorporating the portfolio return in the hedging strategy is to use the risk-return tradeoff (Sharpe measure) criteria. Howard and D'Antonio (1984) consider the optimal level of futures contracts by maximizing the ratio of the portfolio's excess return to its volatility:

$$
\max _{C_{f}} \theta=\frac{E\left(R_{h}\right)-R_{F}}{\sigma_{h}},
$$

where $\sigma_{h}^{2}=\operatorname{Var}\left(R_{h}\right)$ and $R_{F}$ represents the risk-free interest rate. In this case the optimal number of futures positions, $C_{f}^{*}$, is given by:

$$
C_{f}^{*}=-C_{s} \frac{(S / F)\left(\sigma_{s} / \sigma_{f}\right)\left[\left(\sigma_{s} / \sigma_{f}\right)\left(E\left(R_{f}\right) /\left(E\left(R_{s}\right)-R_{F}\right)\right)-\rho\right]}{\left[1-\left(\sigma_{s} / \sigma_{f}\right)\left(E\left(R_{f}\right) \rho /\left(E\left(R_{s}\right)-R_{F}\right)\right)\right]} .
$$

From the optimal futures position, we can obtain the following optimal hedge ratio:

$$
h_{3}=-\frac{\left(\sigma_{s} / \sigma_{f}\right)\left[\left(\sigma_{s} / \sigma_{f}\right)\left(E\left(R_{f}\right) /\left(E\left(R_{s}\right)-R_{F}\right)\right)-\rho\right]}{\left[1-\left(\sigma_{s} / \sigma_{f}\right)\left(E\left(R_{f}\right) \rho /\left(E\left(R_{s}\right)-R_{F}\right)\right)\right]} .
$$

Again, if $E\left(R_{f}\right)=0$, then $h_{3}$ reduces to:

$$
h_{3}=\frac{\sigma_{s}}{\sigma_{f}} \rho,
$$

which is the same as the MV hedge ratio $h_{J}^{*}$.

As pointed out by Chen et al. (2001), the Sharpe ratio is a highly non-linear function of the hedge ratio. Therefore, it is possible that Eq. (7), which is derived by equating the first derivative to zero, may lead to the hedge ratio that would minimize, instead of maximizing, the Sharpe ratio. This would be true if the second derivative of the Sharpe ratio with respect to the hedge ratio is positive instead of negative. Furthermore, it is possible that the optimal hedge ratio may be undefined as in the case encountered by Chen et al. (2001), where the Sharpe ratio monotonically increases with the hedge ratio.

\subsubsection{Maximum expected utility hedge ratio}

So far we have discussed the hedge ratios that incorporate only risk as well as the ones that incorporate both risk and return. The methods, which incorporate both the expected return and risk in the derivation of the optimal hedge ratio, are consistent with the mean-variance 
framework. However, these methods may not be consistent with the expected utility maximization principle unless either the utility function is quadratic or the returns are jointly normally distributed. Therefore, in order to make the hedge ratio consistent with the expected utility maximization principle, we need to derive the hedge ratio that maximizes the expected utility. However, in order to maximize the expected utility we need to assume a specific utility function. For example, Cecchetti et al. (1988) derive the hedge ratio that maximizes the expected utility where the utility function is assumed to be the logarithm of terminal wealth. Specifically, they derive the optimal hedge ratio that maximizes the following expected utility function:

$$
\int_{R_{s}} \int_{R_{f}} \log \left[1+R_{s}-h R_{f}\right] f\left(R_{s}, R_{f}\right) \mathrm{d} R_{s} \mathrm{~d} R_{f},
$$

where the density function $f\left(R_{s}, R_{f}\right)$ is assumed to be bivariate normal. A third-order linear bivariate ARCH model is used to get the conditional variance and covariance matrix, and a numerical procedure is used to maximize the objective function with respect to the hedge ratio. ${ }^{2}$

\subsubsection{Minimum mean extended-Gini coefficient hedge ratio}

This approach of deriving the optimal hedge ratio is consistent with the concept of stochastic dominance and involves the use of the MEG coefficient. Cheung et al. (1990), Kolb and Okunev (1992), Lien and Luo (1993a), Shalit (1995), and Lien and Shaffer (1999) all consider this approach. It minimizes the MEG coefficient $\Gamma_{v}\left(R_{h}\right)$ defined as follows:

$$
\Gamma_{v}\left(R_{h}\right)=-v \operatorname{Cov}\left(R_{h},\left(1-G\left(R_{h}\right)\right)^{v-1}\right),
$$

where $G$ is the cumulative probability distribution and $v$ is the risk aversion parameter. Note that $0 \leq v<1$ implies risk seekers, $v=1$ implies risk-neutral investors, and $v>1$ implies risk-averse investors. Shalit (1995) has shown that if the futures and spot returns are jointly normally distributed, then the minimum-MEG hedge ratio would be the same as the MV hedge ratio.

\subsubsection{Optimum mean-MEG hedge ratio}

Instead of minimizing the MEG coefficient, Kolb and Okunev (1993) alternatively consider maximizing the utility function defined as follows:

$$
U\left(R_{h}\right)=E\left(R_{h}\right)-\Gamma_{v}\left(R_{h}\right) .
$$

The hedge ratio based on the utility function defined by Eq. (10) is denoted as the M-MEG hedge ratio. The difference between the MEG and M-MEG hedge ratios is that the MEG hedge ratio ignores the expected return on the hedged portfolio. Again, if the futures price follows a martingale process (i.e., $E\left(R_{f}\right)=0$ ), then the MEG hedge ratio would be the same as the M-MEG hedge ratio.

\subsubsection{Minimum generalized semivariance hedge ratio}

In recent years a new approach for determining the hedge ratio has been suggested (see Chen et al., 2001; De Jong et al., 1997; Lien \& Tse, 1998, 2000). This new approach is based on the relationship between the GSV and expected utility as discussed by Fishburn (1977) and 
Bawa (1978). In this case the optimal hedge ratio is obtained by minimizing the GSV given below:

$$
V_{\delta, \alpha}\left(R_{h}\right)=\int_{-\infty}^{\delta}\left(\delta-R_{h}\right)^{\alpha} \mathrm{d} G\left(R_{h}\right), \quad \alpha>0,
$$

where $G\left(R_{h}\right)$ is the probability distribution function of the return on the hedged portfolio $R_{h}$. The parameters $\delta$ and $\alpha$ (which are both real numbers) represent the target return and risk aversion, respectively. The risk is defined in such a way that the investors consider only the returns below the target return $(\delta)$ to be risky. It can be shown (see Fishburn, 1977) that $\alpha<1$ represents a risk-seeking investor and $\alpha>1$ represents a risk-averse investor.

The GSV, due to its emphasis on the returns below the target return, is consistent with the risk perceived by managers (see Crum et al., 1981; Lien \& Tse, 2000). Furthermore, as shown by Fishburn (1977) and Bawa (1978), the GSV is consistent with the concept of stochastic dominance. Lien and Tse (1998) show that the GSV hedge ratio, which is obtained by minimizing the GSV, would be the same as the MV hedge ratio if the futures and spot returns are jointly normally distributed and if the futures price follows a pure martingale process.

\subsubsection{Optimum mean-generalized semivariance hedge ratio}

Chen et al. (2001) extend the GSV hedge ratio to a mean-GSV (M-GSV) hedge ratio by incorporating the mean return in the derivation of the optimal hedge ratio. The M-GSV hedge ratio is obtained by maximizing the following mean-risk utility function, which is similar to the conventional mean-variance-based utility function (see Eq. (3)):

$$
U\left(R_{h}\right)=E\left[R_{h}\right]-V_{\delta, \alpha}\left(R_{h}\right) .
$$

This approach to the hedge ratio does not use the risk aversion parameter to multiply the GSV as done in conventional mean-risk models (see Hsin et al., 1994 and Eq. (3)). This is because the risk aversion parameter is already included in the definition of the GSV, $V_{\delta, \alpha}\left(R_{h}\right)$. As before, the M-GSV hedge ratio would be the same as the GSV hedge ratio if the futures price follows a pure martingale process.

\subsection{Dynamic case}

We have up to now examined the situations in which the hedge ratio is fixed at the optimum level and is not revised during the hedging period. However, it could be beneficial to change the hedge ratio over time. One way to allow the hedge ratio to change is by recalculating the hedge ratio based on the current (or conditional) information on the covariance $\left(\sigma_{s f}\right)$ and variance $\left(\sigma_{f}^{2}\right)$. This involves calculating the hedge ratio based on conditional information (i.e., $\sigma_{s f} \mid \Omega_{t-1}$ and $\left.\sigma_{f}^{2} \mid \Omega_{t-1}\right)$ instead of unconditional information. In this case, the MV hedge ratio is given by:

$$
h_{1} \mid \Omega_{t-1}=\frac{\sigma_{s f} \mid \Omega_{t-1}}{\sigma_{f}^{2} \mid \Omega_{t-1}} .
$$

The adjustment to the hedge ratio based on new information can be implemented using such conditional models as ARCH and GARCH (to be discussed later) or using the moving window 
estimation method. Alternatively, we can allow the hedge ratio to change during the hedging period by considering multi-period models, which is the approach used by Lien and Luo (1993b).

Lien and Luo (1993b) consider hedging with $T$ periods' planning horizon and minimize the variance of the wealth at the end of the planning horizon, $W_{T}$. Consider the situation where $C_{s, t}$ is the spot position at the beginning of period $t$ and the corresponding futures position is given by $C_{f, t}=-b_{t} C_{s, t}$. The wealth at the end of the planning horizon, $W_{T}$, is then given by:

$$
\begin{aligned}
W_{T} & =W_{0}+\sum_{t=0}^{T-1} C_{s, t}\left[S_{t+1}-S_{t}-b_{t}\left(F_{t+1}-F_{t}\right)\right] \\
& =W_{0}+\sum_{t=0}^{T-1} C_{s, t}\left[\Delta S_{t+1}-b_{t} \Delta F_{t+1}\right] .
\end{aligned}
$$

The optimal $b_{t}$ 's are given by the following recursive formula:

$$
b_{t}=-\frac{\operatorname{Cov}\left(\Delta S_{t+1}, \Delta F_{t+1}\right)}{\operatorname{Var}\left(\Delta F_{t+1}\right)}-\sum_{i=t+1}^{T-1}\left(\frac{C_{s, i}}{C_{s, t}}\right) \frac{\operatorname{Cov}\left(\Delta F_{t+1}, \Delta S_{i+1}+b_{i} \Delta F_{i+1}\right)}{\operatorname{Var}\left(\Delta F_{t+1}\right)} .
$$

It is clear from Eq. (14) that the optimal hedge ratio $b_{t}$ will change over time. The multi-period hedge ratio will differ from the single-period hedge ratio due to the second term on the right-hand side of Eq. (14). However, it is interesting to note that the multi-period hedge ratio would be different from the single-period one if the changes in current futures prices are correlated with the changes in future futures prices or with the changes in future spot prices.

\subsection{Case with production and alternative investment opportunities}

All the models considered in Sections 2.1 and 2.2 assume that the spot position is fixed or predetermined, and thus production is ignored. As mentioned earlier, such an assumption may be appropriate for financial futures. However, when we consider commodity futures, production should be considered in which case the spot position becomes one of the decision variables. In an important paper, Lence (1995) extends the model with a fixed or predetermined spot position to a model where production is included. In his model, Lence (1995) also incorporates the possibility of investing in a risk-free asset and other risky assets, borrowing, as well as transaction costs. We will briefly discuss the model considered by Lence (1995) below.

Lence (1995) considers a decision maker whose utility is a function of terminal wealth $U\left(W_{1}\right)$, such that $U^{\prime}>0$ and $U^{\prime \prime}<0$. At the decision date $(t=0)$, the decision maker will engage in the production of $Q$ commodity units for sale at terminal date $(t=1)$ at the random cash price $P_{1}$. At the decision date, the decision maker can lend $L$ dollars at the risk-free lending rate $\left(R_{L}-1\right)$ and borrow $B$ dollars at the borrowing rate $\left(R_{B}-1\right)$, invest $I$ dollars in a different activity that yields a random rate of return $\left(R_{I}-1\right)$ and sell $X$ futures at futures price $F_{0}$. The transaction cost for the futures trade is $f$ dollars per unit of the commodity traded to be paid at the terminal date. The terminal wealth $\left(W_{1}\right)$ is therefore given by:

$$
W_{1}=W_{0} R=P_{1} Q+\left(F_{0}-F_{1}\right) X-f|X|-R_{B} B+R_{L} L+R_{I} I,
$$


where $R$ is the return on the diversified portfolio. The decision maker will maximize the expected utility subject to the following restrictions:

$$
\begin{aligned}
& W_{0}+B \geq v(Q) Q+L+I, \quad 0 \leq B \leq k_{B} v(Q) Q, k_{B} \geq 0, \\
& L \geq k_{L} F_{0}|X|, \quad k_{L} \geq 0, I \geq 0,
\end{aligned}
$$

where $v(Q)$ is the average cost function, $k_{B}$ is the maximum amount (expressed as a proportion of his initial wealth) that the agent can borrow, and $k_{L}$ is the safety margin for the futures contract.

Using this framework, Lence (1995) introduces two opportunity costs: opportunity cost of alternative (sub-optimal) investment $\left(c_{\text {alt }}\right)$ and opportunity cost of estimation risk $\left(e^{\text {Bayes }}\right) .{ }^{3}$ Let $R_{\text {opt }}$ be the return of the expected-utility maximizing strategy and let $R_{\text {alt }}$ be the return on a particular alternative (sub-optimal) investment strategy. The opportunity cost of alternative investment strategy $c_{\text {alt }}$ is then given by:

$$
E\left\lfloor U\left(W_{0} R_{\text {opt }}\right)\right\rfloor=E\left[U\left(W_{0} R_{\text {alt }}+c_{\text {alt }}\right)\right] .
$$

In other words, $c_{\text {alt }}$ is the minimum certain net return required by the agent to invest in the alternative (sub-optimal hedging) strategy rather than in the optimum strategy. Using the CARA utility function and some simulation results, Lence (1995) finds that the expected-utility maximizing hedge ratios are substantially different from the minimum variance hedge ratios. He also shows that under certain conditions, the optimal hedge ratio is zero; i.e., the optimal strategy is not to hedge at all.

Similarly, the opportunity cost of the estimation risk $\left(e^{\text {Bayes }}\right)$ is defined as follows:

$$
E_{\rho}\left\lfloor E\left(U\left\{W_{0}\left[R_{\text {opt }}(\rho)-e_{\rho}^{\text {Bayes }}\right]\right\}\right)\right\rfloor=E_{\rho}\left\lfloor E\left(U\left(W_{0} R_{\text {opt }}^{\text {Bayes }}\right)\right)\right\rfloor,
$$

where $R_{\text {opt }}(\rho)$ is the expected-utility maximizing return where the agent knows with certainty the value of the correlation between the futures and spot prices $(\rho), R_{\mathrm{opt}}^{\text {Bayes }}$ is the expected-utility maximizing return where the agent only knows the distribution of the correlation $\rho$, and $E_{\rho}[\cdot]$ is the expectation with respect to $\rho$. Using simulation results, Lence (1995) finds that the opportunity cost of the estimation risk is negligible and thus the value of the use of sophisticated estimation methods is negligible.

\section{Alternative methods for estimating the optimal hedge ratio}

In Section 2 we discussed different approaches to deriving the optimum hedge ratios. However, in order to apply these optimum hedge ratios in practice, we need to estimate these hedge ratios. There are various ways of estimating them. In this section we briefly discuss these estimation methods.

\subsection{Estimation of the MV hedge ratio}

\subsubsection{OLS method}

The conventional approach to estimating the MV hedge ratio involves the regression of the changes in spot prices on the changes in futures price using the OLS technique (e.g., see Junkus 
\& Lee, 1985). Specifically, the regression equation can be written as:

$$
\Delta S_{t}=a_{0}+a_{1} \Delta F_{t}+e_{t}
$$

where the estimate of the MV hedge ratio, $H_{J}$, is given by $a_{1}$. The OLS technique is quite robust and simple to use. However, for the OLS technique to be valid and efficient, assumptions associated with the OLS regression must be satisfied. One case where the assumptions are not completely satisfied is that the error term in the regression is heteroscedastic. This situation will be discussed later.

Another problem with the OLS method, as pointed out by Myers and Thompson (1989), is the fact that it uses unconditional sample moments instead of conditional sample moments, which use currently available information. They suggest the use of the conditional covariance and conditional variance in Eq. (2a). In this case, the conditional version of the optimal hedge ratio (Eq. (2a)) will take the following form:

$$
H_{J}^{*}=\frac{C_{f}}{C_{s}}=\frac{\operatorname{Cov}(\Delta S, \Delta F) \mid \Omega_{t-1}}{\operatorname{Var}(\Delta F) \mid \Omega_{t-1}} .
$$

Suppose that the current information $\left(\Omega_{t-1}\right)$ includes a vector of variables $\left(X_{t-1}\right)$ and the spot and futures price changes are generated by the following equilibrium model:

$$
\Delta S_{t}=X_{t-1} \alpha+u_{t}, \quad \Delta F_{t}=X_{t-1} \beta+v_{t} .
$$

In this case the maximum likelihood estimator of the MV hedge ratio is given by (see Myers \& Thompson, 1989):

$$
\hat{h} \mid X_{t-1}=\frac{\hat{\sigma}_{u v}}{\hat{\sigma}_{v}^{2}},
$$

where $\hat{\sigma}_{u v}$ is the sample covariance between the residuals $u_{t}$ and $v_{t}$, and $\hat{\sigma}_{v}^{2}$ is the sample variance of the residual $v_{t}$. In general, the OLS estimator obtained from Eq. (18) would be different from the one given by Eq. (19). For the two estimators to be the same, the spot and futures prices must be generated by the following model:

$$
\Delta S_{t}=\alpha_{0}+u_{t}, \quad \Delta F_{t}=\beta_{0}+v_{t} .
$$

In other words, if the spot and futures prices follow a random walk with or without drift, then the two estimators will be the same. Otherwise, the hedge ratio estimated from the OLS regression (18) will not be optimal.

\subsubsection{ARCH and GARCH methods}

Ever since the development of ARCH and GARCH models, the OLS method of estimating the hedge ratio has been generalized to take into account the heteroscedastic nature of the error term in Eq. (18). In this case, rather than using the unconditional sample variance and covariance, the conditional variance and covariance from the GARCH model are used in the estimation of the hedge ratio. As mentioned above, such a technique allows an update of the hedge ratio over the hedging period. 
Consider the following bivariate GARCH model (see Baillie \& Myers, 1991; Cecchetti et al., 1988):

$$
\begin{aligned}
& {\left[\begin{array}{l}
\Delta S_{t} \\
\Delta F_{t}
\end{array}\right]=\left[\begin{array}{l}
\mu_{1} \\
\mu_{2}
\end{array}\right]+\left[\begin{array}{l}
e_{1 t} \\
e_{2 t}
\end{array}\right] \Leftrightarrow \Delta Y_{t}=\mu+e_{t},} \\
& e_{t} \mid \Omega_{t-1} \sim N\left(0, H_{t}\right), H_{t}=\left[\begin{array}{ll}
H_{11, t} & H_{12, t} \\
H_{12, t} & H_{22, t}
\end{array}\right], \\
& \operatorname{vec}\left(H_{t}\right)=C+A \operatorname{vec}\left(e_{t-1} e_{t-1}^{\prime}\right)+B \operatorname{vec}\left(H_{t-1}\right) .
\end{aligned}
$$

The conditional MV hedge ratio at time $t$ is given by $h_{t-1}=H_{12, t} / H_{22, t}$. This model allows the hedge ratio to change over time, resulting in a series of hedge ratios instead of a single hedge ratio for the entire hedging horizon.

The model can be extended to include more than one type of cash and futures contracts (see Sephton, 1993a). For example, consider a portfolio that consists of spot wheat $\left(S_{1 t}\right)$, spot canola $\left(S_{2 t}\right)$, wheat futures $\left(F_{1 t}\right)$ and canola futures $\left(F_{2 t}\right)$. We then have the following multi-variate GARCH model:

$$
\left[\begin{array}{c}
\Delta S_{1 t} \\
\Delta S_{2 t} \\
\Delta F_{1 t} \\
\Delta F_{2 t}
\end{array}\right]=\left[\begin{array}{l}
\mu_{1} \\
\mu_{2} \\
\mu_{3} \\
\mu_{4}
\end{array}\right]+\left[\begin{array}{l}
e_{1 t} \\
e_{2 t} \\
e_{3 t} \\
e_{4 t}
\end{array}\right] \Leftrightarrow \Delta Y_{t}=\mu+e_{t}, \quad e_{t}\left|\Omega_{t-1}\right| \sim N\left(0, H_{t}\right) .
$$

The MV hedge ratio can be estimated using a similar technique as described above. For example, the conditional MV hedge ratio is given by the conditional covariance between the spot and futures price changes divided by the conditional variance of the futures price change.

\subsubsection{Random coefficient method}

There is another way to deal with heteroscedasticity. This involves use of the random coefficient model as suggested by Grammatikos and Saunders (1983). This model employs the following variation of Eq. (18):

$$
\Delta S_{t}=\beta_{0}+\beta_{t} \Delta F_{t}+e_{t},
$$

where the hedge ratio $\beta_{t}=\bar{\beta}+v_{t}$ is assumed to be random. This random coefficient model can, in some cases, improve the effectiveness of hedging strategy. However, this technique does not allow for the update of the hedge ratio over time even though the correction for the randomness can be made in the estimation of the hedge ratio.

\subsubsection{Cointegration and error correction method}

The techniques described so far do not take into consideration the possibility that spot price and futures price series could be non-stationary. If these series have unit roots, then this will raise a different issue. If the two series are cointegrated as defined by Engle and Granger (1987), then the regression Eq. (18) will be mis-specified and an error-correction term must be included in the equation. Since the arbitrage condition ties the spot and futures prices, they cannot drift far apart in the long run. Therefore, if both series follow a random walk, then we expect the two series to be cointegrated in which case we need to estimate the error correction model. This calls for the use of the cointegration analysis. 
The cointegration analysis involves two steps. First, each series must be tested for a unit root (e.g., see Dickey \& Fuller, 1981; Phillips \& Perron, 1988). Second, if both series are found to have a single unit root, then the cointegration test must be performed (e.g., see Engle \& Granger, 1987; Johansen \& Juselius, 1990; Osterwald-Lenum, 1992).

If the spot price and futures price series are found to be cointegrated, then the hedge ratio can be estimated in two steps (see Chou et al., 1996; Ghosh, 1993). The first step involves the estimation of the following cointegrating regression:

$$
S_{t}=a+b F_{t}+u_{t}
$$

The second step involves the estimation of the following error correction model:

$$
\Delta S_{t}=\rho u_{t-1}+\beta \Delta F_{t}+\sum_{i=1}^{m} \delta_{i} \Delta F_{t-i}+\sum_{j=1}^{n} \theta_{i} \Delta S_{t-j}+e_{j},
$$

where $u_{t}$ is the residual series from the cointegrating regression. The estimate of the hedge ratio is given by the estimate of $\beta$. Some researchers (e.g., see Lien \& Luo, 1993b) assume that the long-run cointegrating relationship is $\left(S_{t}-F_{t}\right)$, and estimate the following error correction model:

$$
\Delta S_{t}=\rho\left(S_{t-1}-F_{t-1}\right)+\beta \Delta F_{t}+\sum_{i=1}^{m} \delta_{i} \Delta F_{t-i}+\sum_{j=1}^{n} \theta_{i} \Delta S_{t-j}+e_{j} .
$$

Alternatively, Chou et al. (1996) suggest the estimation of the error correction model as follows:

$$
\Delta S_{t}=\alpha \hat{u}_{t-1}+\beta \Delta F_{t}+\sum_{i=1}^{m} \delta_{i} \Delta F_{t-i}+\sum_{j=1}^{n} \theta_{i} \Delta S_{t-j}+e_{j},
$$

where $\hat{u}_{t-1}=S_{t-1}-\left(a+b F_{t-1}\right)$; i.e., the series $\hat{u}_{t}$ is the estimated residual series from Eq. (21). The hedge ratio is given by $\beta$ in Eq. (24).

Kroner and Sultan (1993) combine the error-correction model with the GARCH model considered by Cecchetti et al. (1988) and Baillie and Myers (1991) in order to estimate the optimum hedge ratio. Specifically, they use the following model:

$$
\left[\begin{array}{l}
\Delta \log _{e}\left(S_{t}\right) \\
\Delta \log _{e}\left(F_{t}\right)
\end{array}\right]=\left[\begin{array}{l}
\mu_{1} \\
\mu_{2}
\end{array}\right]+\left[\begin{array}{c}
\alpha_{s}\left(\log _{e}\left(S_{t-1}\right)-\log _{e}\left(F_{t-1}\right)\right) \\
\alpha_{f}\left(\log _{e}\left(S_{t-1}\right)-\log _{e}\left(F_{t-1}\right)\right)
\end{array}\right]+\left[\begin{array}{l}
e_{1 t} \\
e_{2 t}
\end{array}\right],
$$

where the error processes follow a GARCH process. As before, the hedge ratio at time $(t-1)$ is given by $h_{t-1}=H_{12, t} / H_{22, t}$.

\subsection{Estimation of the optimum mean-variance and Sharpe hedge ratios}

The optimum mean-variance and Sharpe hedge ratios are given by Eqs. (4) and (7), respectively. These hedge ratios can be estimated simply by replacing the theoretical moments by their sample moments. For example, the expected returns can be replaced by sample average returns, the standard deviations can be replaced by the sample standard deviations, and the correlation can be replaced by sample correlation. 


\subsection{Estimation of the maximum expected utility hedge ratio}

The maximum expected utility hedge ratio involves the maximization of the expected utility. This requires the estimation of distributions of the changes in spot and futures prices. Once the distributions are estimated, one needs to use a numerical technique to get the optimum hedge ratio. One such method is described in Cecchetti et al. (1988) where an ARCH model is used to estimate the required distributions.

\subsection{Estimation of MEG coefficient based hedge ratios}

The MEG hedge ratio involves the minimization of the following MEG coefficient:

$$
\Gamma_{v}\left(R_{h}\right)=-v \operatorname{Cov}\left[R_{h},\left(1-G\left(R_{h}\right)\right)^{v-1}\right] .
$$

In order to estimate the MEG coefficient, we need to estimate the cumulative probability density function $G\left(R_{h}\right)$. The cumulative probability density function is usually estimated by ranking the observed return on the hedged portfolio. A detailed description of the process can be found in Kolb and Okunev (1992), and we briefly describe the process here.

The cumulative probability distribution is estimated by using the rank as follows:

$$
G\left(R_{h, i}\right)=\frac{\operatorname{Rank}\left(R_{h, i}\right)}{N}
$$

where $N$ is the sample size. Once we have the series for the probability distribution function, the MEG is estimated by replacing the theoretical covariance by the sample covariance as follows:

$$
\Gamma_{v}^{\text {sample }}\left(R_{h}\right)=-\frac{v}{N} \sum_{i=1}^{N}\left(R_{h, i}-\bar{R}_{h}\right)\left(\left(1-G\left(R_{h, i}\right)\right)^{v-1}-\Theta\right),
$$

where

$$
\bar{R}_{h}=\frac{1}{N} \sum_{i=1}^{N} R_{h, i} \quad \text { and } \quad \Theta=\frac{1}{N} \sum_{i=1}^{N}\left(1-G\left(R_{h, i}\right)\right)^{v-1} .
$$

The optimal hedge ratio is now given by the hedge ratio that minimizes the estimated MEG. Since there is no analytical solution, the numerical method needs to be applied in order to get the optimal hedge ratio. This method is sometimes referred to as the empirical distribution method.

Alternatively, the instrumental variable (IV) method suggested by Shalit (1995) can be used to find the MEG hedge ratio. Shalit's method provides the following analytical solution for the MEG hedge ratio:

$$
h^{\mathrm{IV}}=\frac{\operatorname{Cov}\left(S_{t+1},\left[1-G\left(F_{t+1}\right)\right]^{v-1}\right)}{\operatorname{Cov}\left(F_{t+1},\left[1-G\left(F_{t+1}\right)\right]^{v-1}\right)} .
$$

It is important to note that for the IV method to be valid, the cumulative distribution function of the terminal wealth $\left(W_{t+1}\right)$ should be similar to the cumulative distribution of the futures price $\left(F_{t+1}\right)$; i.e., $G\left(W_{t+1}\right)=G\left(F_{t+1}\right)$. Lien and Shaffer (1999) find that the IV-based hedge ratio $\left(h^{\mathrm{IV}}\right)$ is significantly different from the minimum MEG hedge ratio. 
Lien and Luo (1993a) suggest an alternative method of estimating the MEG hedge ratio. This method involves the estimation of the cumulative distribution function using a non-parametric kernel function instead of using a rank function as suggested above.

Regarding the estimation of the M-MEG hedge ratio, one can follow either the empirical distribution method or the non-parametric kernel method to estimate the MEG coefficient. A numerical method can then be used to estimate the hedge ratio that maximizes the objective function given by Eq. (10).

\subsection{Estimation of GSV-based hedge ratios}

The GSV can be estimated from the sample by using the following sample counterpart:

$$
V_{\delta, \alpha}^{\text {sample }}\left(R_{h}\right)=\frac{1}{N} \sum_{i=1}^{N}\left(\delta-R_{h, i}\right)^{\alpha} U\left(\delta-R_{h, i}\right),
$$

where

$$
U\left(\delta-R_{h, i}\right)= \begin{cases}1, & \text { for } \delta \geq R_{h, i} \\ 0, & \text { for } \delta<R_{h, i} .\end{cases}
$$

Similar to the MEG technique, the optimal GSV hedge ratio can be estimated by choosing the hedge ratio that minimizes the sample GSV, $V_{\delta, \alpha}^{\text {sample }}\left(R_{h}\right)$. Numerical methods can be used to search for the optimum hedge ratio. Similarly, the M-GSV hedge ratio can be obtained by minimizing the mean-risk function given by Eq. (12), where the expected return on the hedged portfolio is replaced by the sample average return and the GSV is replaced by the sample GSV.

One can instead use the kernel density estimation method suggested by Lien and Tse (2000) to estimate the GSV, and numerical techniques can be used to find the optimum GSV hedge ratio. Instead of using the kernel method, one can also employ the conditional heteroscedastic model to estimate the density function. This is the method used by Lien and Tse (1998).

\section{Hedging horizon, maturity of futures contract, data frequency, and hedging effectiveness}

In this section we discuss the relationship among the length of hedging horizon (hedging period), maturity of futures contracts, data frequency (e.g., daily, weekly, monthly, or quarterly), and hedging effectiveness. Since there are many futures contracts (with different maturities) that can be used in hedging, the question is whether the MV hedge ratio depends on the time to maturity of the futures contract being used for hedging. Lee, Bubnys, and Lin (1987) find that the MV hedge ratio increases as the maturity is approached. This means that if we use the nearest to maturity futures contracts to hedge, then the MV hedge ratio will be larger compared to the one obtained using futures contracts with a longer maturity.

Aside from using futures contracts with different maturities, we can estimate the MV hedge ratio using data with different frequencies. For example, the data used in the estimation of the optimum hedge ratio can be daily, weekly, monthly, or quarterly. At the same time, the hedging horizon could be from a few hours to more than a month. The question is whether a relationship exists between the data frequency used and the length of the hedging horizon. 
Malliaris and Urrutia (1991) and Benet (1992) utilize Eq. (18) and weekly data to estimate the optimal hedge ratio. According to Malliaris and Urrutia (1991), the ex ante hedging is more effective when the hedging horizon is 1 week compared to a hedging horizon of 4 weeks. Benet (1992) finds that a shorter hedging horizon (4 weeks) is more effective (in ex ante test) compared to a longer hedging horizon ( 8 and 12 weeks). These empirical results seem to be consistent with the argument that when estimating the MV hedge ratio, the hedging horizon's length must match the data frequency being used.

There is a potential problem associated with matching the length of the hedging horizon and the data frequency. For example, consider the case where the hedging horizon is 3 months (one-quarter). In this case we need to use quarterly data to match the length of the hedging horizon. In other words, when estimating Eq. (18) we must employ quarterly changes in spot and futures prices. Therefore, if we have 5 years' worth of data, then we will have 19 non-overlapping price changes, resulting in a sample size of 19 . However, if the hedging horizon is 1 week, instead of 3 months, then we will end up with approximately 260 non-overlapping price changes (sample size of 260) for the same 5 years' worth of data. Therefore, the matching method is associated with a reduction in sample size for a longer hedging horizon.

One way to get around this problem is to use overlapping price changes. For example, Geppert (1995) utilizes $k$-period differencing for a $k$-period hedging horizon in estimating the regression-based MV hedge ratio. Since Geppert (1995) uses approximately 13 months of data for estimating the hedge ratio, he employs overlapping differencing in order to eliminate the reduction in sample size caused by differencing. However, this will lead to correlated observations instead of independent observations and will require the use of a regression with autocorrelated errors in the estimation of the hedge ratio.

In order to eliminate the autocorrelated errors problem, Geppert (1995) suggests a method based on cointegration and unit-root processes. We will briefly describe his method. Suppose that the spot and futures prices, which are both unit-root processes, are cointegrated. In this case the futures and spot prices can be described by the following processes (see Hylleberg \& Mizon, 1989; Stock \& Watson, 1988):

$$
\begin{aligned}
S_{t} & =A_{1} P_{t}+A_{2} \tau_{t}, \\
F_{t} & =B_{1} P_{t}+B_{2} \tau_{t}, \\
P_{t} & =P_{t-1}+w_{t}, \\
\tau_{t} & =\alpha_{1} \tau_{t-1}+v_{t}, \quad 0 \leq\left|\alpha_{1}\right|<1,
\end{aligned}
$$

where $P_{t}$ and $\tau_{t}$ are permanent and transitory factors that drive the spot and futures prices and $w_{t}$ and $v_{t}$ are white noise processes. Note that $P_{t}$ follows a pure random walk process and $\tau_{t}$ follows a stationary process. The MV hedge ratio for a $k$-period hedging horizon is then given by (see Geppert, 1995):

$$
H_{J}^{*}=\frac{A_{1} B_{1} k \sigma_{w}^{2}+2 A_{2} B_{2}\left(\left(1-\alpha^{k}\right) /\left(1-\alpha^{2}\right)\right) \sigma_{v}^{2}}{B_{1}^{2} k \sigma_{w}^{2}+2 B_{2}^{2}\left(\left(1-\alpha^{k}\right) /\left(1-\alpha^{2}\right)\right) \sigma_{v}^{2}} .
$$

One advantage of using Eq. (29) instead of a regression with non-overlapping price changes is that it avoids the problem of a reduction in sample size associated with non-overlapping differencing. 


\section{Summary and conclusions}

In this paper we have reviewed various approaches to deriving the optimal hedge ratio, as summarized in Appendix A. These approaches can be divided into the mean-variance-based approach, the expected utility maximizing approach, the mean extended-Gini coefficient-based approach, and the generalized semivariance-based approach. All these approaches will lead to the same hedge ratio as the conventional MV hedge ratio if the futures price follows a pure martingale process and if the futures and spot prices are jointly normal. However, if these conditions do not hold, then the hedge ratios based on the various approaches will be different.

The MV hedge ratio is the most understood and most widely-used hedge ratio. Since the statistical properties of the MV hedge ratio are well known, statistical hypothesis testing can be performed with the MV hedge ratio. For example, we can test whether the optimal MV hedge ratio is the same as the naïve hedge ratio. Since the MV hedge ratio ignores the expected return, it will not be consistent with the mean-variance analysis unless the futures price follows a pure martingale process. Furthermore, if the martingale and normality condition do not hold, then the MV hedge ratio will not be consistent with the expected utility maximization principle. Following the MV hedge ratio is the mean-variance hedge ratio. Even if this hedge ratio incorporates the expected return in the derivation of the optimal hedge ratio, it will not be consistent with the expected maximization principle unless either the normality condition holds or the utility function is quadratic.

In order to make the hedge ratio consistent with the expected utility maximization principle, we can derive the optimal hedge ratio by maximizing the expected utility. However, to implement such approach, we need to assume a specific utility function and we need to make an assumption regarding the return distribution. Therefore, different utility functions will lead to different optimal hedge ratios. Furthermore, analytic solutions for such hedge ratios are not known and numerical methods need to be applied.

New approaches have recently been suggested in deriving optimal hedge ratios. These include the mean-Gini coefficient-based hedge ratio as well as semivariance-based hedge ratios. These hedge ratios are consistent with the second-order stochastic dominance principle. Therefore, such hedge ratios are very general in the sense that they are consistent with the expected utility maximization principle and make very few assumptions on the utility function. The only requirement is that the marginal utility be positive and the second derivative of the utility function be negative. However, both of these hedge ratios do not lead to a unique hedge ratio. For example, the mean-Gini coefficient-based hedge ratio depends on the risk aversion parameter $(v)$ and the semivariance-based hedge ratio depends on the risk aversion parameter $(\alpha)$ and target return $(\delta)$. It is important to note, however, that the semivariance-based hedge ratio has some appeal in the sense that the semivariance as a measure of risk is consistent with the risk perceived by individuals.

So far as the derivation of the optimal hedge ratio is concerned, almost all of the derivations do not incorporate transaction costs. Furthermore, these derivations do not allow investments in securities other than the spot and corresponding futures contracts. As shown by Lence (1995), once we relax these conventional assumptions, the resulting optimal hedge ratio can be quite different from the ones obtained under the conventional assumptions. Lence's (1995) results are 
based on a specific utility function and some other assumption regarding the return distributions. It remains to be seen if such results hold for the mean extended-Gini coefficient-based as well as semivariance-based hedge ratios.

In this paper we have also reviewed various ways of estimating the optimum hedge ratio, as summarized in Appendix B. As far as the estimation of the conventional MV hedge ratio is concerned, there are a large number of methods that have been proposed in the literature. These methods range from a simple regression method to complex cointegrated heteroscedastic methods, and some of the estimation methods include a kernel density function method as well as an empirical distribution method. Except for many of mean-variance-based hedge ratios, the estimation involves the use of a numerical technique. This has to do with the fact that most of the optimal hedge ratio formulae do not have a closed-form analytic expression. Again, it is important to mention that based on his specific model, Lence (1995) finds that the value of complicated and sophisticated estimation methods is negligible. It remains to be seen if such a result holds for the mean extended-Gini coefficient-based as well as semivariance-based hedge ratios.

In this paper we have also discussed about the relationship between the optimal MV hedge ratio and the hedging horizon. We feel that this relationship has not been fully explored and can be further developed in the future. For example, we would like to know if the optimal hedge ratio approaches the naïve hedge ratio when the hedging horizon becomes longer.

The main thing we learn from this review is that if the futures price follows a pure martingale process and if the returns are jointly normally distributed, then all different hedge ratios are the same as the conventional MV hedge ratio, which is simple to compute and easy to understand. However, if these two conditions do not hold, then there are many optimal hedge ratios (depending on which objective function one is trying to optimize) and there is no single optimal hedge ratio that is distinctly superior to the remaining ones. Therefore, further research needs to be done to unify these different approaches to the hedge ratio.

For those who are interested in research in this area, we would like to finally point out that one requires a good understanding of financial economic theories and econometric methodologies. In addition, a good background in data analysis and computer programming would also be helpful.

\section{Notes}

1. Without loss of generality, we assume that the size of the futures contract is one.

2. Lence (1995) also derives the hedge ratio based on the expected utility. We will discuss it later in Section 2.3.

3. Our discussion of the opportunity costs is very brief. We would like to refer interested readers to Lence (1995) for a detailed discussion. We would also like to point to the fact that production can be allowed to be random as is done in Lence (1996).

\section{Acknowledgments}

We would like to thank an anonymous referee for helpful comments. Any remaining errors are the authors'. 
Appendix A. Theoretical models

\begin{tabular}{|c|c|c|}
\hline References & $\begin{array}{l}\text { Return definition and } \\
\text { objective function }\end{array}$ & Summary \\
\hline Johnson (1960) & $\operatorname{Ret}_{1}, O_{1}$ & $\begin{array}{l}\text { The paper derives the minimum variance hedge ratio. The hedging } \\
\text { effectiveness is defined as } E_{1} \text {, but no empirical analysis is done }\end{array}$ \\
\hline Hsin et al. (1994) & $\operatorname{Ret}_{2}, O_{2}$ & $\begin{array}{l}\text { The paper derives the utility function-based hedge ratio. A new measure } \\
\text { of hedging effectiveness } E_{2} \text { based on a certainty equivalent is proposed. } \\
\text { The new measure of hedging effectiveness is used to compare the } \\
\text { effectiveness of futures and options as hedging instruments }\end{array}$ \\
\hline $\begin{array}{l}\text { Howard and D' Antonio } \\
\text { (1984) }\end{array}$ & $\operatorname{Ret}_{2}, O_{3}$ & $\begin{array}{l}\text { The paper derives the optimal hedge ratio based on maximizing the } \\
\text { Sharpe ratio. The proposed hedging effectiveness } E_{3} \text { is based on the } \\
\text { Sharpe ratio }\end{array}$ \\
\hline Cecchetti et al. (1988) & $\operatorname{Ret}_{2}, O_{4}$ & $\begin{array}{l}\text { The paper derives the optimal hedge ratio that maximizes the expected } \\
\text { utility function: } \int_{R_{s}} \int_{R_{f}} \log \left[1+R_{s}(t)-h(t) R_{f}(t)\right] f_{t}\left(R_{s}, R_{f}\right) \mathrm{d} R_{s} \mathrm{~d} R_{f} \text {, } \\
\text { where the density function is assumed to be bivariate normal. A } \\
\text { third-order linear bivariate ARCH model is used to get the conditional } \\
\text { variance and covariance matrix. A numerical procedure is used to } \\
\text { maximize the objective function with respect to hedge ratio. Due to } \\
\text { ARCH, the hedge ratio changes over time. The paper uses certainty } \\
\text { equivalent }\left(E_{2}\right) \text { to measure the hedging effectiveness }\end{array}$ \\
\hline Cheung et al. (1990) & $\operatorname{Ret}_{2}, O_{5}$ & $\begin{array}{l}\text { The paper uses mean-Gini ( } v=2 \text {, not mean extended-Gini coefficient) } \\
\text { and mean-variance approaches to analyze the effectiveness of options } \\
\text { and futures as hedging instruments }\end{array}$ \\
\hline Kolb and Okunev (1992) & $\operatorname{Ret}_{2}, O_{5}$ & $\begin{array}{l}\text { The paper uses mean extended-Gini coefficient in the derivation of the } \\
\text { optimal hedge ratio. Therefore, it can be considered as a generalization } \\
\text { of the mean-Gini coefficient method used by Cheung et al. (1990) }\end{array}$ \\
\hline
\end{tabular}
optimal hedge ratio. Therefore, it can be considered as a generalization of the mean-Gini coefficient method used by Cheung et al. (1990) 
Appendix A. (Continued)

\begin{tabular}{|c|c|c|}
\hline References & $\begin{array}{l}\text { Return definition and } \\
\text { objective function }\end{array}$ & Summary \\
\hline Kolb and Okunev (1993) & $\operatorname{Ret}_{2}, O_{6}$ & $\begin{array}{l}\text { The paper defines the objective function as } O_{6} \text {, but in terms of wealth } \\
(W) U(W)=E[W]-\Gamma_{v}(W) \text { and compares with the quadratic utility } \\
\text { function } U(W)=E[W]-m \sigma^{2} \text {. The paper plots the EMG efficient } \\
\text { frontier in } W \text { and } \Gamma_{v}(W) \text { space for various values of risk aversion } \\
\text { parameters }(v)\end{array}$ \\
\hline Lien and Luo (1993b) & $\operatorname{Ret}_{1}, O_{9}$ & $\begin{array}{l}\text { The paper derives the multi-period hedge ratios where the hedge ratios } \\
\text { are allowed to change over the hedging period. The method suggested in } \\
\text { the paper still falls under the minimum variance hedge ratio }\end{array}$ \\
\hline Lence (1995) & $\mathrm{O}_{4}$ & $\begin{array}{l}\text { This paper derives the expected utility maximizing hedge ratio where the } \\
\text { terminal wealth depends on the return on a diversified portfolio that } \\
\text { consists of the production of a spot commodity, investment in a risk-free } \\
\text { asset, investment in a risky asset, as well as borrowing. It also } \\
\text { incorporates the transaction costs }\end{array}$ \\
\hline De Jong et al. (1997) & $\begin{array}{l}\operatorname{Ret}_{2}, O_{7}(\text { also } \\
\left.\text { uses } O_{1} \text { and } O_{3}\right)\end{array}$ & $\begin{array}{l}\text { The paper derives the optimal hedge ratio that minimizes the GSV. The } \\
\text { paper compares the GSV hedge ratio with the MV hedge ratio as well as } \\
\text { the Sharpe hedge ratio. The paper uses } E_{1} \text { (for the MV hedge ratio), } E_{3} \\
\text { (for the Sharpe hedge ratio) and } E_{4} \text { (for the GSV hedge ratio) as the } \\
\text { measures of hedging effectiveness }\end{array}$ \\
\hline Chen et al. (2001) & $\operatorname{Ret}_{1}, O_{8}$ & $\begin{array}{l}\text { The paper derives the optimal hedge ratio that maximizes the risk-return } \\
\text { function given by } U\left(R_{h}\right)=E\left[R_{h}\right]-V_{\delta, \alpha}\left(R_{h}\right) \text {. The method can be } \\
\text { considered as an extension of the GSV method used by De Jong et al. } \\
\text { (1997) }\end{array}$ \\
\hline
\end{tabular}


Notes:

A. Return model

$\left(\operatorname{Ret}_{1}\right)$

$\left(\operatorname{Ret}_{2}\right)$

$\Delta V_{H}=C_{s} \Delta P_{s}+C_{f} \Delta P_{f} \Rightarrow$ hedge ratio $=H=\frac{C_{f}}{C_{s}}, C_{s}=$ units of spot commodity and $C_{f}=$ units of futures contract

$R_{h}=R_{s}+h R_{f}, \quad R_{s}=\frac{S_{t}-S_{t-1}}{S_{t-1}}$, (a) $R_{f}=\frac{F_{t}-F_{t-1}}{F_{t-1}} \Rightarrow$ hedge ratio $: h=\frac{C_{f} F_{t-1}}{C_{s} S_{t-1}}$,

(b) $R_{f}=\frac{F_{t}-F_{t-1}}{S_{t-1}} \Rightarrow$ hedge ratio : $h=\frac{C_{f}}{C_{s}}$.

B. Objective function

$\left(O_{1}\right)$ Minimize

$\operatorname{Var}\left(R_{h}\right)=C_{s}^{2} \sigma_{s}^{2}+C_{f}^{2} \sigma_{f}^{2}+2 C_{s} C_{f} \sigma_{s f}$ or $\operatorname{Var}\left(R_{h}\right)=\sigma_{s}^{2}+h^{2} \sigma_{f}^{2}+2 h \sigma_{s f}$

$\left(\mathrm{O}_{2}\right)$ Maximize

$\left(\mathrm{O}_{3}\right)$ Maximize

$\left(\mathrm{O}_{4}\right)$ Maximize

$\left(\mathrm{O}_{5}\right)$ Minimize

$\left(O_{6}\right)$ Maximize

$\left(\mathrm{O}_{7}\right)$ Minimize

$\left(\mathrm{O}_{8}\right)$ Maximize

$\left(O_{9}\right)$ Minimize

$E\left(R_{h}\right)-A \frac{1}{2} \operatorname{Var}\left(R_{h}\right)$

$\frac{E\left(R_{h}\right)-R_{F}}{\operatorname{Var}\left(R_{h}\right)}$ (Sharpe ratio), $R_{F}=$ risk-free interest rate

$E[U(W)], U(\cdot)=$ utility function, $W=$ terminal wealth

$\Gamma_{v}\left(R_{h}\right), \Gamma_{v}\left(R_{h}\right)=-v \operatorname{Cov}\left(R_{h},\left(1-F\left(R_{h}\right)\right)^{v-1}\right)$

$E\left[R_{h}\right]-\Gamma_{v}\left(R_{h} v\right)$

$V_{\delta, \alpha}\left(R_{h}\right)=\int_{-\infty}^{\delta}\left(\delta-R_{h}\right)^{\alpha} \mathrm{d} G\left(R_{h}\right), \quad \alpha>0$

$U\left(R_{h}\right)=E\left[R_{h}\right]-V_{\delta, \alpha}\left(R_{h}\right)$

$\operatorname{Var}\left(W_{t}\right)=\operatorname{Var}\left(\sum_{t=1}^{T} C_{s, t} \Delta S_{t}+C_{f, t} \Delta F\right)$.

C. Hedging effectiveness

$e=1-\frac{\operatorname{Var}\left(R_{h}\right)}{\operatorname{Var}\left(R_{S}\right)}$

$e=R_{h}^{\mathrm{ce}}-R_{s s}^{\mathrm{ce}}, R_{h}^{\mathrm{ce}}\left(R_{s}^{\mathrm{ce}}\right)=$ certainty equivalent return of hedged (unhedged) portfolio

$e=\frac{\left(E\left[R_{h}\right]-R_{F}\right) / \operatorname{Var}\left(R_{h}\right)}{\left(E\left[R_{s}\right]-R_{F}\right) / \operatorname{Var}\left(R_{S}\right)}$ or $e=\frac{E\left[R_{h}\right]-R_{F}}{\operatorname{Var}\left(R_{h}\right)}-\frac{E\left[R_{s}\right]-R_{F}}{\operatorname{Var}\left(R_{S}\right)}$

$\left(E_{4}\right)$

$e=1-\frac{V_{\delta, \alpha}\left(R_{h}\right)}{V_{\delta, \alpha}\left(R_{S}\right)}$ 
Appendix B. Empirical models

\begin{tabular}{ll}
\hline References & Commodity \\
\hline Ederington (1979) & GNMA futures \\
& $(1 / 1976-12 / 1977)$, wheat \\
& $(1 / 1976-12 / 1977)$, corn \\
& $(1 / 1976-12 / 1977)$, T-bill \\
& futures $(3 / 1976-12 / 1977)$ \\
& [weekly data] \\
& \\
& \\
& Swiss franc, Canadian dollar, \\
& British pound, DM, Yen \\
Grammatikos and & (1/1974-6/1980) [weekly \\
Saunders (1983) & data]
\end{tabular}

Junkus and Lee (1985) Three stock index futures for Kansas City Board of Trade, New York Futures Exchange, and Chicago Mercantile Exchange (5/82-3/83) [daily data]
Summary

The paper uses the Ret $_{1}$ definition of return and estimates the minimum variance hedge ratio $\left(O_{1}\right) . E_{1}$ is used as a hedging effectiveness measure. The paper uses nearby contracts (3-6 months, 6-9 months and 9-12 months) and a hedging period of 2 and 4 weeks. OLS $\left(M_{1}\right)$ is used to estimate the parameters. Some of the hedge ratios are found not to be different from zero and the hedging effectiveness increases with the length of hedging period. The hedge ratio also increases (closer to unity) with the length of hedging period

The paper estimates the hedge ratio for the whole period and moving window (2-year data). It is found that the hedge ratio changes over time. Dummy variables for various sub-periods are used, and shifts are found. The paper uses a random coefficient $\left(M_{3}\right)$ model to estimate the hedge ratio. The hedge ratio for Swiss franc is found to follow a random coefficient model. However, there is no improvement in effectiveness when the hedge ratio is calculated by correcting for the randomness

The paper tests the applicability of four futures hedging models: a variance-minimizing model introduced by Johnson (1960), the traditional one to one hedge, a utility maximization model developed by Rutledge (1972), and a basis arbitrage model suggested by Working (1953). An optimal ratio or decision rule is estimated for each model, and measures for the effectiveness of each hedge are devised. Each hedge strategy performed best according to its own criterion. The working decision rule appeared to be easy to use and satisfactory in most cases. 
Lee et al. (1987)

Cecchetti et al. (1988)

Cheung et al. (1990)
S\&P 500, NYSE, Value Line (1983) [daily data]

Treasury bond, Treasury bond futures $(1 / 1978-5 / 1986)$

[monthly data]

Swiss franc, Canadian dollar, British pound, German mark, Japanese yen (9/1983-12/1984) [daily data]
Although the maturity of the futures contract used affected the size of the optimal hedge ratio, there was no consistent maturity effect on performance. Use of a particular ratio depends on how closely the assumptions underlying the model approach a hedger's real situation

The paper tests for the temporal stability of the minimum variance hedge ratio. It is found that the hedge ratio increases as maturity of the futures contract nears. The paper also performs a functional form test and finds support for the regression of rate of change for discrete as well as continuous rates of change in prices

The paper derives the hedge ratio by maximizing the expected utility. A third-order linear bivariate ARCH model is used to get the conditional variance and covariance matrix. A numerical procedure is used to maximize the objective function with respect to the hedge ratio. Due to $\mathrm{ARCH}$, the hedge ratio changes over time. It is found that the hedge ratio changes over time and is significantly less (in absolute value) than the MV hedge ratio (which also changes over time). $E_{2}$ (certainty equivalent) is used to measure the performance effectiveness. The proposed utility-maximizing hedge ratio performs better than the MV hedge ratio

The paper uses mean-Gini coefficient $(v=2)$ and mean-variance approaches to analyze the effectiveness of options and futures as hedging instruments. It considers both mean-variance and expected-return mean-Gini coefficient frontiers. It also considers the MV and minimum mean-Gini coefficient hedge ratios. The MV and minimum mean-Gini approaches indicate that futures is a better hedging instrument. However, the mean-variance frontier indicates futures to be a better hedging instrument whereas the mean-Gini frontier indicates options to be a better hedging instrument 
Appendix B. (Continued)

\begin{tabular}{ll}
\hline References & Commodity \\
\hline $\begin{array}{l}\text { Baillie and Myers } \\
\text { (1991) }\end{array}$ & Beef, coffee, corn, cotton, \\
& gold, soybean (contracts \\
& maturing in 1982 and 1986) \\
[daily data]
\end{tabular}

Summary

The paper uses a bivariate GARCH model $\left(M_{2}\right)$ in estimating the MV hedge ratios. Since the models used are conditional models, the time series of hedge ratios are estimated. The MV hedge ratios are found to follow a unit root process. The hedge ratio for beef is found to be centered around zero. $E_{1}$ is used as a hedging effectiveness measure. Both in-sample and out-of-sample effectiveness of the GARCH-based hedge ratios is compared with a constant hedge ratio. The GARCH-based hedge ratios are found to be significantly better compared to the constant hedge ratio

Malliaris and Urrutia (1991)

Benet (1992)
British pound, German mark, Japanese yen, Swill franc, Canadian dollar $(3 / 1980-12 / 1988)$ [weekly data]

Australian dollar, Brazilian cruzeiro, Mexican peso, South African rand, Chinese yuan, Finish markka, Irish pound, Japanese yen (8/1973-12/1985) [weekly data]
The paper uses regression autocorrelated errors model to estimate the MV hedge ratio for the five currencies. Using overlapping moving windows, the time series of the MV hedge ratio and hedging effectiveness are estimated for both ex post (in-sample) and $e x$ ante (out-of-sample) cases. $E_{1}$ is used to measure the hedging effectiveness for the ex post case whereas average return is used to measure the hedging effectiveness. Specifically, the average return close to zero is used to indicate a better performing hedging strategy. In the ex post case, the 4-week hedging horizon is more effective compared to the 1-week hedging horizon. However, for the ex ante case the opposite is found to be true

This paper considers direct and cross-hedging, using multiple futures contracts. For minor currencies, the cross-hedging exhibits a significant decrease in performance from ex post to ex ante. The minimum variance hedge ratios are found to change from one period to the other except for the direct hedging of Japanese yen. On the ex ante case, the hedging effectiveness does not appear to be related to the estimation period length. However, the effectiveness decreases as the hedging period length increases 
Kolb and Okunev

(1992)

Kolb and Okunev (1993)

Lien and Luo (1993a)
Corn, copper, gold, German mark, S\&P 500 (1989) [daily data]

Cocoa (3/1952 to 1976$)$ for four cocoa-producing countries (Ghana, Nigeria, Ivory Coast, and Brazil) [March and September data]

S\&P 500 (1/1984-12/1988) [weekly data]
The paper estimates the MEG hedge ratio $\left(M_{9}\right)$ with $v$ ranging from 2 to 200. The MEG hedge ratios are found to be close to the minimum variance hedge ratios for a lower level of risk parameter $v$ (for $v$ from 2 to 5). For higher values of $v$, the two hedge ratios are found to be quite different. The hedge ratios are found to increase with the risk aversion parameter for S\&P 500, corn, and gold. However, for copper and German mark, the hedge ratios are found to decrease with the risk aversion parameter. The hedge ratio tends to be more stable for higher levels of risk

The paper estimates the M-MEG hedge ratio $\left(M_{12}\right)$. The paper compares the M-MEG hedge ratio, minimum variance hedge ratio, and optimum mean-variance hedge ratio for various values of risk aversion parameters. The paper finds that the M-MEG hedge ratio leads to reverse hedging (buy futures instead of selling) for $v$ less than 1.24 (Ghana case). For high-risk aversion parameter values (high $v$ ) all hedge ratios are found to converge to the same value

The paper points out that the MEG hedge ratio can be calculated either by numerically optimizing the MEG coefficient or by numerically solving the first-order condition. For $v=9$ the hedge ratio of -0.8182 is close to the MV hedge ratio of -0.8171 .

Using the first-order condition, the paper shows that for a large $v$ the MEG hedge ratio converges to a constant. The empirical result shows that the hedge ratio decreases with the risk aversion parameter $v$. The paper finds that the MV and MEG hedge ratio (for low $v$ ) series (obtained by using a moving window) are more stable compared to the MEG hedge ratio for a large $v$. The paper also uses a non-parametric Kernel estimator to estimate the cumulative density function. However, the kernel estimator does not change the result significantly 
Appendix B. (Continued)

\begin{tabular}{ll}
\hline References & Commodity \\
\hline Lien and Luo (1993b) & British pound, Canadian \\
dollar, German mark, \\
Japanese yen, Swiss franc \\
(3/1980-12/1988), MMI, \\
NYSE, S\&P \\
$(1 / 1984-12 / 1988)$ [weekly \\
data]
\end{tabular}

Summary

Ghosh (1993) S\&P futures, S\&P index, Dow Jones industrial average, NYSE composite index (1/1990-12/1991) [daily data]

This paper proposes a multi-period model to estimate the optimal hedge ratio. The hedge ratios are estimated using an error-correction model. The spot and futures prices are found to be cointegrated. The optimal multi-period hedge ratios are found to exhibit a cyclical pattern with a tendency for the amplitude of the cycles to decrease. Finally, the possibility of spreading among different market contracts is analyzed. It is shown that hedging in a single market may be much less effective than the optimal spreading strategy

All the variables are found to have a unit root. For all three indices the same S\&P 500 futures contracts are used (cross-hedging). Using the Engle-Granger two-step test, the S\&P 500 futures price is found to be cointegrated with each of the three spot prices: S\&P 500, DJIA, and NYSE. The hedge ratio is estimated using the error-correction model (ECM) $\left(M_{4}\right)$.

Out-of-sample performance is better for the hedge ratio from the ECM compared to the Ederington model

Sephton (1993a) $\quad$ Feed wheat, canola futures (1981-1982 crop year) [daily data]

The paper finds unit roots on each of the cash and futures (log) prices, but no cointegration between futures and spot (log) prices. The hedge ratios are computed using a four-variable

GARCH $(1,1)$ model. The time series of hedge ratios are found to be stationary. Reduction in portfolio variance is used as a measure of hedging effectiveness. It is found that the

GARCH-based hedge ratio performs better compared to the conventional minimum variance hedge ratio

Sephton (1993b) Feed wheat, feed barley, canola futures (1988/1989)

The paper finds unit roots on each of the cash and futures (log) prices, but no cointegration between futures and spot (log) prices. [daily data] 
Kroner and Sultan (1993)

Hsin et al. (1994)

Shalit (1995)
British pound, Canadian dollar, German mark, Japanese yen, Swiss franc (2/1985-2/1990) [weekly data]

British pound, German mark, Yen, Swiss franc (1/1986-12/1989) [daily data]

Gold, silver, copper, aluminum (1/1977-12/1990) [daily data] futures are not significantly different from zero. However, from the bivariate GARCH canola is found to have a significant mean return. For canola the mean-variance utility function is used to find the optimal hedge ratio for various values of the risk aversion parameter. The time series of the hedge ratio (based on bivariate GARCH model) is found to be stationary. The benefit in terms of utility gained from using a multi-variate GARCH decreases as the degree of risk aversion increases

The paper uses the error-correction model with a GARCH error $\left(M_{5}\right)$ to estimate the MV hedge ratio for the five currencies. Due to the use of conditional models, the time series of the MV hedge ratios are estimated. Both within-sample and out-of-sample evidence shows that the hedging strategy proposed in the paper is potentially superior to the conventional strategies

The paper derives the optimum mean-variance hedge ratio by maximizing the objective function $\mathrm{O}_{2}$. The hedging horizons of $14,30,60,90$, and 120 calendar days are considered to compare the hedging effectiveness of options and futures contracts. It is found that the futures contracts perform better than the options contracts

The paper shows that if the prices are jointly normally distributed, the MEG hedge ratio will be same as the MV hedge ratio. The MEG hedge ratio is estimated using the instrumental variable method. The paper performs normality tests as well as the tests to see if the MEG hedge ratios are different from the MV hedge ratios. The paper finds that for a significant number of futures contracts the normality does not hold and the MEG hedge ratios are different from the MV hedge ratios 
Appendix B. (Continued)

\begin{tabular}{|c|c|c|}
\hline References & Commodity & Summary \\
\hline Geppert (1995) & $\begin{array}{l}\text { German mark, Swiss franc, } \\
\text { Japanese yen, S\&P 500, } \\
\text { Municipal Bond Index } \\
(1 / 1990-1 / 1993) \text { [weekly } \\
\text { data] }\end{array}$ & $\begin{array}{l}\text { The paper estimates the minimum variance hedge ratio using the } \\
\text { OLS as well as the cointegration methods for various lengths of } \\
\text { hedging horizon. The in-sample results indicate that for both } \\
\text { methods the hedging effectiveness increases with the length of } \\
\text { the hedging horizon. The out-of-sample results indicate that in } \\
\text { general the effectiveness (based on the method suggested by } \\
\text { Malliaris \& Urrutia, 1991) decreases as the length of the hedging } \\
\text { horizon decreases. This is true for both the regression method and } \\
\text { the decomposition method proposed in the paper. However, the } \\
\text { decomposition method seems to perform better than the } \\
\text { regression method in terms of both mean and variance }\end{array}$ \\
\hline De Jong et al. (1997) & $\begin{array}{l}\text { British pound } \\
(12 / 1976-10 / 1993), \text { German } \\
\text { mark }(12 / 1976-10 / 1993), \\
\text { Japanese yen } \\
(4 / 1977-10 / 1993) \text { [daily data] }\end{array}$ & $\begin{array}{l}\text { The paper compares the minimum variance, generalized } \\
\text { semivariance and Sharpe hedge ratios for the three currencies. } \\
\text { The paper computes the out-of-sample hedging effectiveness } \\
\text { using non-overlapping } 90 \text {-day periods where the first } 60 \text { days are } \\
\text { used to estimate the hedge ratio and the remaining } 30 \text { days are } \\
\text { used to compute the out-of-sample hedging effectiveness. The } \\
\text { paper finds that the naïve hedge ratio performs better than the } \\
\text { model based hedge ratios }\end{array}$ \\
\hline Lien and Tse (1998) & $\begin{array}{l}\text { Nikkei Stock Average } \\
\text { (1/1989-8/1996) [daily data] }\end{array}$ & $\begin{array}{l}\text { The paper shows that if the rates of change in spot and futures } \\
\text { prices are bivariate normal and if the futures price follows a } \\
\text { martingale process, then the GSV (referred to as lower partial } \\
\text { moment) hedge ratio will be same as the MV hedge ratio. A } \\
\text { version of the bivariate asymmetric power ARCH model is used }\end{array}$ \\
\hline
\end{tabular}


Lien and Shaffer (1999)

Lien and Tse (2000)

Nikkei Stock Average (1/1988-8/996) [daily data]

Chen et al. (2001)
Nikkei (9/86-9/89), S\&P

(4/82-4/85), TOPIX

(4/90-12/93), KOSPI

(5/96-12/96), Hang Seng

(1/87-12189), IBEX

(4/93-3/95) [daily data]

to estimate the conditional joint distribution, which is then used to estimate the time varying GSV hedge ratios. The paper finds that the GSV hedge ratio significantly varies over time and is different from the MV hedge ratio

This paper empirically tests the ranking assumption used by Shalit (1995). The ranking assumption assumes that the ranking of futures prices is the same as the ranking of the wealth. The paper estimates the MEG hedge ratio based on the instrumental variable (IV) method used by Shalit (1995) and the true MEG hedge ratio. The true MEG hedge ratio is computed using the cumulative probability distribution estimated employing the kernel method instead of the rank method. The paper finds that the MEG hedge ratio obtained from the IV method to be different from the true MEG hedge ratio. Furthermore, the true MEG hedge ratio leads to a significantly smaller MEG coefficient compared to the IV-based MEG hedge ratio

The paper estimates the GSV hedge ratios for different values of parameters using a non-parametric kernel estimation method. The kernel method is compared with the empirical distribution method. It is found that the hedge ratio from one method is not different from the hedge ratio from another. The Jarque-Bera (1987) test indicates that the changes in spot and futures prices do not follow normal distribution

The paper proposes the use of the M-GSV hedge ratio. The paper estimates the MV, optimum mean-variance, Sharpe, MEG, GSV, M-MEG, and M-GSV hedge ratios. The Jarque-Bera (1987) test and D'Agostino (1971) D Statistic indicate that the price changes

S\&P $500(4 / 982-12 / 1991)$ [weekly data] 


References Commodity Summary

are not normally distributed. Furthermore, the expected value of the futures price change is found to be significantly different from zero. It is also found that for a high level of risk aversion, the M-MEG hedge ratio converges to the MV hedge ratio whereas the M-GSV hedge ratio converges to a lower value

Notes:

A. Minimum variance hedge ratio

A.1. OLS

$\left(M_{1}\right): \quad \Delta S_{t}=a_{0}+a_{1} \Delta F_{t}+e_{t}: \quad$ hedge ratio $=a_{1}$

$R_{s}=a_{0}+a_{1} R_{f}+e_{t}:$ hedge ratio $=a_{1}$

\section{A.2. ARCH/GARCH}

$$
\left(M_{2}\right): \quad\left[\begin{array}{l}
\Delta S_{t} \\
\Delta F_{t}
\end{array}\right]=\left[\begin{array}{l}
\mu_{1} \\
\mu_{2}
\end{array}\right]+\left[\begin{array}{l}
e_{1, t} \\
e_{2, t}
\end{array}\right], \quad e_{t} \mid \Omega_{t-1} \sim N\left(0, H_{t}\right), H_{t}=\left[\begin{array}{ll}
H_{11, t} & H_{12, t} \\
H_{12, t} & H_{22, t}
\end{array}\right], \quad \text { hedge ratio }=\frac{H_{12, t}}{H_{22, t}}
$$

\section{A.3. Random coefficient}

$$
\begin{array}{ll}
\left(M_{3}\right): & \Delta S_{t}=\beta_{0}+\beta_{t} \Delta F_{t}+e_{t} \\
& \beta_{t}=\bar{\beta}+v_{t}, \quad \text { hedge ratio }=\bar{\beta}
\end{array}
$$

A.4. Cointegration and error-correction

$$
\begin{array}{ll}
\left(M_{4}\right): & S_{t}=a+b F_{t}+u_{t} \\
& \Delta S_{t}=\rho u_{t-1}+\beta \Delta F_{t}+\sum_{i=1}^{m} \delta_{i} \Delta F_{t-i}+\sum_{j=1}^{n} \theta_{i} \Delta S_{t-j}+e_{j}, \quad \text { hedge ratio }=\beta
\end{array}
$$

A.5. Error-correction with GARCH

$$
\begin{aligned}
\left(M_{5}\right): & {\left[\begin{array}{l}
\Delta \log _{e}\left(S_{t}\right) \\
\Delta \log _{e}\left(F_{t}\right)
\end{array}\right]=\left[\begin{array}{l}
\mu_{1} \\
\mu_{2}
\end{array}\right]+\left[\begin{array}{c}
\alpha_{s}\left(\log _{e}\left(S_{t-1}\right)-\log _{e}\left(F_{t-1}\right)\right) \\
\alpha_{f}\left(\log _{e}\left(S_{t-1}\right)-\log _{e}\left(F_{t-1}\right)\right)
\end{array}\right]+\left[\begin{array}{l}
e_{1 t} \\
e_{2 t}
\end{array}\right], \quad e_{t} \mid \Omega_{t-1} \sim N\left(0, H_{t}\right), } \\
& H_{t}=\left[\begin{array}{ll}
H_{11, t} & H_{12, t} \\
H_{12, t} & H_{22, t}
\end{array}\right], \quad \text { hedge ratio }=h_{t-1}=\frac{H_{12, t}}{H_{22, t}}
\end{aligned}
$$


A.6. Common stochastic trend
$\left(M_{6}\right): \quad S_{t}=A_{1} P_{t}+A_{2} \tau_{t}$,
$F_{t}=B_{1} P_{t}+B_{2} \tau_{t}$
$P_{t}=P_{t-1}+w_{t}$,
$\tau_{t}=\alpha_{1} \tau_{t-1}+v_{t}, \quad 0 \leq\left|\alpha_{1}\right|<1$,
Hedge ratio for $k$-period investment horizon $=H_{J}^{*}=\frac{A_{1} B_{1} k \sigma_{w}^{2}+2 A_{2} B_{2}\left(\left(1-\alpha^{k}\right) /\left(1-\alpha^{2}\right)\right) \sigma_{v}^{2}}{B_{1}^{2} k \sigma_{w}^{2}+2 B_{2}^{2}\left(\left(1-\alpha^{k}\right) /\left(1-\alpha^{2}\right)\right) \sigma_{v}^{2}}$.

B. Optimum mean-variance hedge ratio

$\left(M_{7}\right): \quad$ Hedge ratio $=h_{2}=-\frac{C_{f}^{*} F}{C_{s} S}=-\left[\frac{E\left(R_{f}\right)}{A \sigma_{f}^{2}}-\rho \frac{\sigma_{s}}{\sigma_{f}}\right]$, where the moments $E\left\lfloor R_{f}\right\rfloor, \sigma_{s}$ and $\sigma_{f}$ are estimated by sample moments.

C. Sharpe hedge ratio $\begin{aligned}\left(M_{8}\right): \quad & \text { Hedge ratio }=h_{3}=-\frac{\left(\sigma_{s} / \sigma_{f}\right)\left[\left(\sigma_{s} / \sigma_{f}\right)\left(E\left(R_{f}\right) /\left(E\left(R_{s}\right)-i\right)\right)-\rho\right]}{\left[1-\left(\sigma_{s} / \sigma_{f}\right)\left(E\left(R_{f}\right) \rho /\left(E\left(R_{s}\right)-i\right)\right)\right]} \text {, where the moments and correlation are } \\ & \text { estimated by their sample counterparts. }\end{aligned}$

D. Mean-Gini coefficient based hedge ratios

$\left(M_{9}\right)$ : The hedge ratio is estimated by numerically minimizing the following mean extended-Gini coefficient, where the cumulative probability distribution function is estimated using the rank function:

$$
\hat{\Gamma}_{v}\left(R_{h}\right)=-\frac{v}{N} \sum_{i=1}^{N}\left(R_{h, i}-\bar{R}_{h}\right)\left(\left(1-G\left(R_{h, i}\right)\right)^{v-1}-\Theta\right) \text {. }
$$

$\left(M_{10}\right)$ : The hedge ratio is estimated by numerically solving the first-order condition, where the cumulative probability distribution function is estimated using the rank function

$\left(M_{11}\right)$ : The hedge ratio is estimated by numerically solving the first-order condition, where the cumulative probability distribution function is estimated using the kernel-based estimates

$\left(M_{12}\right)$ : The hedge ratio is estimated by numerically maximizing the following function: $U\left(R_{h}\right)=E\left(R_{h}\right)-\Gamma_{v}\left(R_{h}\right)$, where the expected values and the mean extended-Gini coefficient are replaced by their sample counterparts and the cumulative probability distribution function is estimated using the rank function

E. Generalized semivariance based hedge ratios

$\left(M_{13}\right)$ : The hedge ratio is estimated by numerically minimizing the following sample generalized hedge ratio:

$V_{\delta, \alpha}^{\text {sample }}\left(R_{h}\right)=\frac{1}{N} \sum_{i=1}^{N}\left(\delta-R_{h, i}\right)^{\alpha} U\left(\delta-R_{h, i}\right)$, where $U\left(\delta-R_{h, i}\right)= \begin{cases}1, & \text { for } \delta \geq R_{h, i} \\ 0, & \text { for } \delta<R_{h, i}\end{cases}$

$\left(M_{14}\right)$ : The hedge ratio is estimated by numerically maximizing the following function: $U\left(R_{h}\right)=R_{h}-V_{\delta, \alpha}^{\text {sample }}\left(R_{h}\right)$. 


\section{References}

Baillie, R. T., \& Myers, R. J. (1991). Bivariate Garch estimation of the optimal commodity futures hedge. Journal of Applied Econometrics, 6, 109-124.

Bawa, V. S. (1978). Safety-first, stochastic dominance, and optimal portfolio choice. Journal of Financial and Quantitative Analysis, 13, 255-271.

Benet, B. A. (1992). Hedge period length and ex ante futures hedging effectiveness: The case of foreign-exchange risk cross hedges. Journal of Futures Markets, 12, 163-175.

Cecchetti, S. G., Cumby, R. E., \& Figlewski, S. (1988). Estimation of the optimal futures hedge. Review of Economics and Statistics, 70, 623-630.

Chen, S. S., Lee, C. F., \& Shrestha, K. (2001). On a mean-generalized semivariance approach to determining the hedge ratio. Journal of Futures Markets, 21, 581-598.

Cheung, C. S., Kwan, C. C. Y., \& Yip, P. C. Y. (1990). The hedging effectiveness of options and futures: A mean-Gini approach. Journal of Futures Markets, 10, 61-74.

Chou, W. L., Fan, K. K., \& Lee, C. F. (1996). Hedging with the Nikkei index futures: The conventional model versus the error correction model. Quarterly Review of Economics and Finance, 36, 495-505.

Crum, R. L., Laughhunn, D. L., \& Payne, J. W. (1981). Risk-seeking behavior and its implications for financial models. Financial Management, 10, 20-27.

D'Agostino, R. B. (1971). An omnibus test of normality for moderate and large size samples. Biometrika, 58, 341-348.

De Jong, A., De Roon, F., \& Veld, C. (1997). Out-of-sample hedging effectiveness of currency futures for alternative models and hedging strategies. Journal of Futures Markets, 17, 817-837.

Dickey, D. A., \& Fuller, W. A. (1981). Likelihood ratio statistics for autoregressive time series with a unit root. Econometrica, 49, 1057-1072.

Ederington, L. H. (1979). The hedging performance of the new futures markets. Journal of Finance, 34, 157-170.

Engle, R. F., \& Granger, C. W. (1987). Co-integration and error correction: Representation, estimation and testing. Econometrica, 55, 251-276.

Fishburn, P. C. (1977). Mean-risk analysis with risk associated with below-target returns. American Economic Review, 67, 116-126.

Geppert, J. M. (1995). A statistical model for the relationship between futures contract hedging effectiveness and investment horizon length. Journal of Futures Markets, 15, 507-536.

Ghosh, A. (1993). Hedging with stock index futures: Estimation and forecasting with error correction model. Journal of Futures Markets, 13, 743-752.

Grammatikos, T., \& Saunders, A. (1983). Stability and the hedging performance of foreign currency futures. Journal of Futures Markets, 3, 295-305.

Howard, C. T., \& D'Antonio, L. J. (1984). A risk-return measure of hedging effectiveness. Journal of Financial and Quantitative Analysis, 19, 101-112.

Hsin, C. W., Kuo, J., \& Lee, C. F. (1994). A new measure to compare the hedging effectiveness of foreign currency futures versus options. Journal of Futures Markets, 14, 685-707.

Hylleberg, S., \& Mizon, G. E. (1989). Cointegration and error correction mechanisms. Economic Journal, 99, $113-125$.

Jarque, C. M., \& Bera, A. K. (1987). A test for normality of observations and regression residuals. International Statistical Review, 55, 163-172.

Johansen, S., \& Juselius, K. (1990). Maximum likelihood estimation and inference on cointegration-with applications to the demand for money. Oxford Bulletin of Economics and Statistics, 52, 169-210.

Johnson, L. L. (1960). The theory of hedging and speculation in commodity futures. Review of Economic Studies, $27,139-151$.

Junkus, J. C., \& Lee, C. F. (1985). Use of three index futures in hedging decisions. Journal of Futures Markets, 5 , 201-222.

Kolb, R. W., \& Okunev, J. (1992). An empirical evaluation of the extended mean-Gini coefficient for futures hedging. Journal of Futures Markets, 12, 177-186. 
Kolb, R. W., \& Okunev, J. (1993). Utility maximizing hedge ratios in the extended mean Gini framework. Journal of Futures Markets, 13, 597-609.

Kroner, K. F., \& Sultan, J. (1993). Time-varying distributions and dynamic hedging with foreign currency futures. Journal of Financial and Quantitative Analysis, 28, 535-551.

Lee, C. F., Bubnys, E. L., \& Lin, Y. (1987). Stock index futures hedge ratios: Test on horizon effects and functional form. Advances in Futures and Options Research, 2, 291-311.

Lence, S. H. (1995). The economic value of minimum variance hedges. American Journal of Agricultural Economics, 77, 353-364.

Lence, S. H. (1996). Relaxing the assumptions of minimum variance hedging. Journal of Agricultural and Resource Economics, 21, 39-55.

Lien, D., \& Luo, X. (1993a). Estimating the extended mean-Gini coefficient for futures hedging. Journal of Futures Markets, 13, 665-676.

Lien, D., \& Luo, X. (1993b). Estimating multiperiod hedge ratios in cointegrated markets. Journal of Futures Markets, 13, 909-920.

Lien, D., \& Shaffer, D. R. (1999). Note on estimating the minimum extended Gini hedge ratio. Journal of Futures Markets, 19, 101-113.

Lien, D., \& Tse, Y. K. (1998). Hedging time-varying downside risk. Journal of Futures Markets, 18, 705-722.

Lien, D., \& Tse, Y. K. (2000). Hedging downside risk with futures contracts. Applied Financial Economics, 10, 163-170.

Malliaris, A. G., \& Urrutia, J. L. (1991). The impact of the lengths of estimation periods and hedging horizons on the effectiveness of a hedge: Evidence from foreign currency futures. Journal of Futures Markets, 3, 271-289.

Myers, R. J., \& Thompson, S. R. (1989). Generalized optimal hedge ratio estimation. American Journal of Agricultural Economics, 71, 858-868.

Osterwald-Lenum, M. (1992). A note with quantiles of the asymptotic distribution of the maximum likelihood cointegration rank test statistics. Oxford Bulletin of Economics and Statistics, 54, 461-471.

Phillips, P. C. B., \& Perron, P. (1988). Testing unit roots in time series regression. Biometrika, 75, 335-346.

Rutledge, D. J. S. (1972). Hedgers' demand for futures contracts: A theoretical framework with applications to the United States soybean complex. Food Research Institute Studies, 11, 237-256.

Sephton, P. S. (1993a). Hedging wheat and canola at the Winnipeg commodity exchange. Applied Financial Economics, 3, 67-72.

Sephton, P. S. (1993b). Optimal hedge ratios at the Winnipeg commodity exchange. Canadian Journal of Economics, 26, 175-193.

Shalit, H. (1995). Mean-Gini hedging in futures markets. Journal of Futures Markets, 15, 617-635.

Stock, J. H., \& Watson, M. W. (1988). Testing for common trends. Journal of the American Statistical Association, 83, 1097-1107.

Working, H. (1953). Hedging reconsidered. Journal of Farm Economics, 35, 544-561. 